\title{
Evaluation of the Incidence and Severity of Olive Leaf Spot Caused by Spilocaea oleagina on Olive Trees in Palestine
}

\author{
Mazen Salman ${ }^{1 *}$, Abd-Almonem Hawamda ${ }^{1}$, Ahmad Al-Ashqar Amarni ${ }^{1}$, Mahmoud Rahil ${ }^{1}$, \\ Hajaj Hajjeh $^{1}$, Basel Natsheh ${ }^{1}$, Ruba Abuamsha ${ }^{2}$ \\ ${ }^{1}$ Technical and Applied Research Center (TARC), Palestine Technical University-Kadoorie (PTUK), Tulkarm, West Bank, Palestine; \\ ${ }^{2}$ National Agriculture Research Center (NARC), Jenin, West Bank, Palestine. \\ Email: *salman_mazen@yahoo.de
}

Received June $18^{\text {th }}$, 2011; revised July $14^{\text {th }}$, 2011; accepted August 22 ${ }^{\text {nd }}, 2011$.

\begin{abstract}
Olive Leaf Spot (OLS) is found in many parts of the world and cause readuced growth and yield in olive trees. In this study, investigations were carried out to measure the incidence (\% infected leaves) and severity (number of lesions/leaf) of OLS in olive growing regions in Palestine, including the regions of Hebron, Bethlehem, Tulkarm, Salfit, Jenin, Nablus, Ramallah and Qalqilyah. OLS was found in all study areas with significantly higher percent incidences in Jenin and Nablus $(67.16 \% \pm 18.16 \%$ and $46.06 \% \pm 23.70 \%$, respectively). OLS was more severe in Nablus, Qalqilyah, Jenin and Tulkarm (severity grade 3.0 - 3.7). Analysis indicate that there is a positive correlation $\left(R^{2}=0.597\right)$ between disease incidence and severity. OLS appeared to be particularly severe on trees that were growing in regions with higher annual rainfall. The correlation between severity and rainfall was positive $\left(R^{2}=0.543\right)$.
\end{abstract}

Keywords: Palestine, Spilocaea oleagina, Peacock Spot, Disease Severity, Olea Europaea

\section{Introduction}

Olive tree (Olea europaea L.) is the most important fruit tree in Palestine covering approximately $45 \%$ of the Palestinian agricultural land [1]. The tree is distinctly important in the economic and social life of the people, comprising one of the main sources of income, reaching its contribution to the good years to about $13 \%$ of the annual agricultural production [1]. One of the most widespread fungal diseases on olive trees is the Olive Leaf Spot (OLS), also known as Peacock Spot disease caused by the fungus Spilocaea oleagina (Castagne) Hughes [2].

The disease is common worldwide and serious in cooler olive-growing regions, with yield losses estimated up to $20 \%$ [2]. The principal symptoms of OLS are dark green to black spots surrounded by a yellow halo on leaves. Petioles, fruit and stems are susceptible but rarely have lesions [3]. The disease causes severe premature defoliation of olive, and sometimes leads to twig death resulting in a subsequent loss in crop yield [4]. Infection of fruit can delay in ripening and a decrease in oil yield, causing unacceptable blemishes on table olives [2].
Chemical fungicides are the principal method used to control OLS throughout olive-growing regions of the world. In olive-growing regions, which are characterized by long dry summers, OLS is controlled by application of copper-containing fungicides prior to winter rains [3]. However, timing of the fungicide applications was reported to be critical for effective control of the disease [5]. In additoin to that, the use of fungicides against the disease is limitted beacuase of their high costs and possible effects on human health and the environment. Regardless of material, the application rate or number of applications, copper containing fungicides will control OLS when disease risk is low [3]. Moreover, regular annual treatment is required to prevent disease build-up in the grove, as high disease levels may be difficult to reduce [6].

Control of OLS disease in Palestine is limited due to the lack of control methods, and due to the fact that the costs of control will reduce the economic income of the farmers. Many copper products are used to reduce infection of the disease. However, the Palestinian farmers avoid spraying in order to keep the production of olive oil devoid from chemicals advantage. Despite the high 
importance of olive tree in Palestine, little informations are available about pests and diseases attaking the tree. The aim of this work was to conduct a field survay to assess the incidence (\% infected leaves) and severity (number of lesions/leaf) of OLS in different regions in Palestine.

\section{Materials and Methods}

A field assessment was conducted during the summer 2010 on olive trees in different regions in Palestine including Hebron, Bethlehem, Ramallah, Nablus, Qalqilyah, Tulkarm, Salfit, Jenin and Tubas (Figure 1). About 20 trees (20 - 30 years old) from infested groove in each district were sampled randomly. On each tree, 100 leaves were randomly selected on the surrounding four sides of the tree and taken to the laboratory for evaluation of disease incidence and severity. Leaves were dipped in 5\% $\mathrm{NaOH}$ for $5 \mathrm{~min}$ and the number of lesions was counted. Disease incidence was determined by recoding the percent of infected leaves per tree. For disease severity, the number of lesions per leaf was counted and graded; 1 (1 lesion), 2 (2 lesions), 3 (3 - 5 lesions), 4 (6 - 10 lesions) or 5 (> 11 lesions) [7].

For statistical analysis, data on the percent of infected leaves were Log-transformed. All data were analyzed for variance by Analysis of Variance (ANOVA). Significant differences among treatments were computed after Tukey HSD test at $P<0.05$.

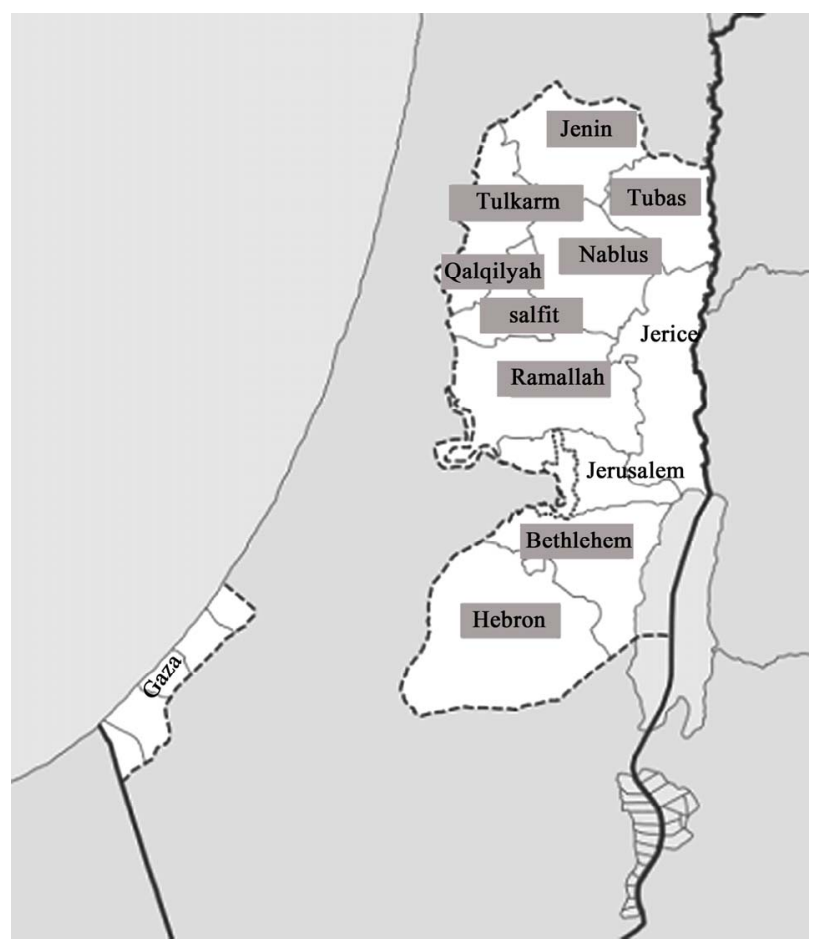

Figure 1. Map of the West Bank and the regions surveyed.

\section{Results}

It was found that all regions are infected with the Olive Leaf Spot disease (OLS). Investigations showed that three (Hebron, Bethlehem and Tubas) of the nine regions surveyed have lowest percentage of leaves infected with OLS ( $F=8.73$, df $=8, P<0.05$ ) (Figure 2). The highest disease incidence was recorded in Jenin (67.2\%) followed by Nablus (46.06\%). The lowest incidence (11.3\%) is measured in Tubas (Figure 2).

The disease severity (Figure 3) was also calculated for OLS in all regions. The severity is significantly different between regions ( $F=9.17$, $\mathrm{df}=8, P<0.05)$. Higher severity (grade 4 ) was recorded in Nablus and Qalqilyah followed by Jenin, Tulkarm, Salfit and Ramallah (grade 3). The lowest disease severity was recorded in Tubas and Bethlehem (grade 2) followed by Hebron (grade 1).

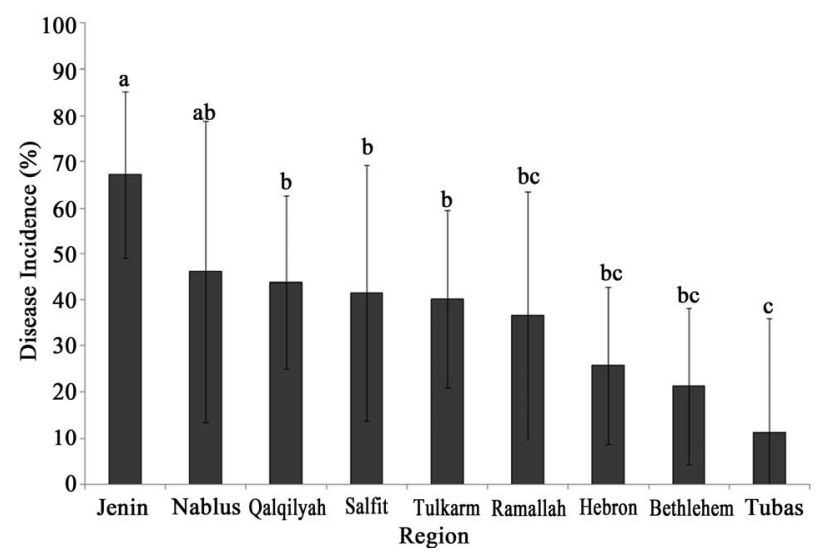

Figure 2. Disease incidence of Olive Leaf Spot (OLS) in different regions in Palestine. Data with different letters are significantly different after Tukeys HSD test using ANOVA at $P<0.05$.

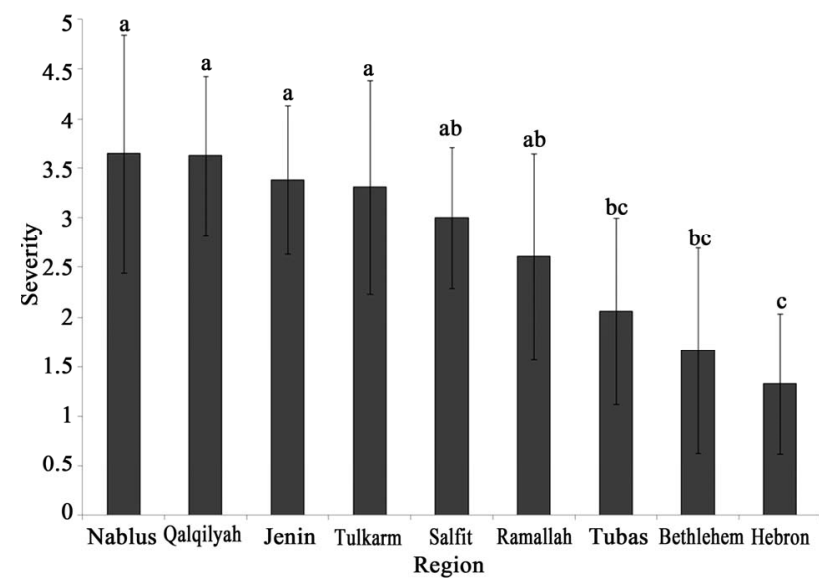

Figure 3. Severity of Olive Leaf Spot (OLS) in different regions in Palestine. Data with different letters are significantly different after Tukeys HSD test using ANOVA at $\boldsymbol{P}<$ 0.05 . 
The relationship between disease incidence and disease severity is described by a linear regression (Figure 4). A positively significant correlation $\left(R^{2}=0.597\right)$ was recorded between incidence and severity.

Interestingly, the prevalence of OLS significantly increases with the mean annual rainfall (Figure 5). The relationship $\left(R^{2}=0.543\right)$ between rainfall and disease incidence was positively correlated (Figure 5).

\section{Discussion}

Olive Leaf Spot (OLS) disease is found in many parts of the world and was recognized in the Mediterranean areas for over a century [8]. The assessment of OLS levels is

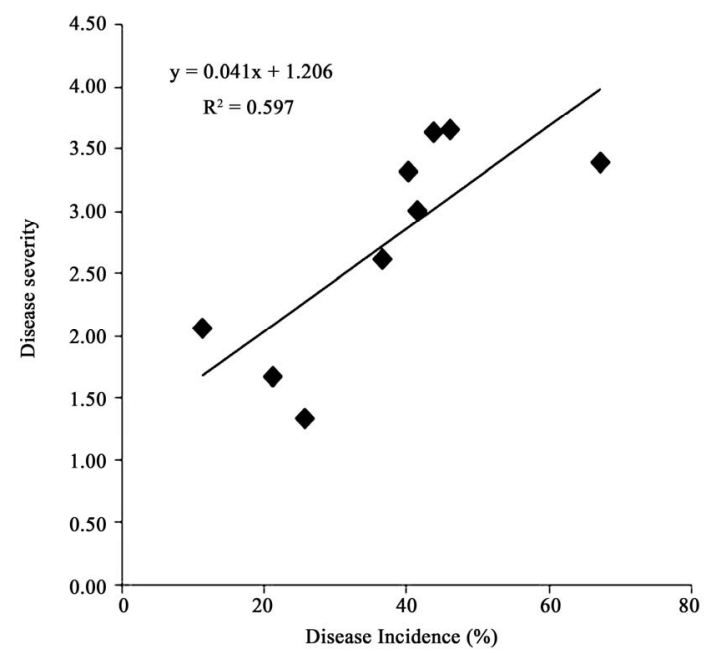

Figure 4. Relationship between disease incidence (\% of infected leaves and severity (number of lesions per leaf) across all trees and assessment regions.

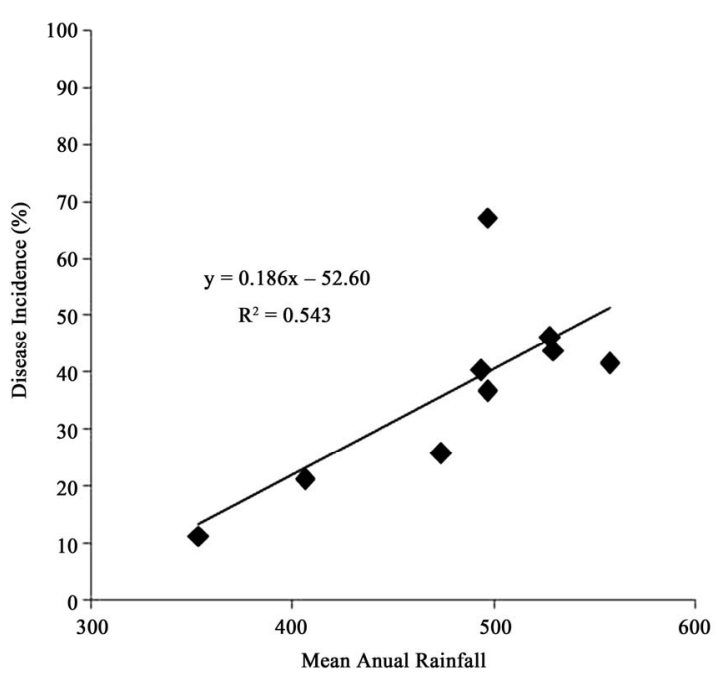

Figure 5. Relationship between mean annual rainfall and disease incidence. Annual rainfall data were obtained from the Palestinian Meteorological Department website. usually indicated by incidence or severity [9]. For many plant diseases, severity is considered to give an accurate indication of disease effect on plants [9]. However, visual estimation of disease severity can vary between assessors whereas assessment of disease incidence is faster and more objective [10]. In this study disease incidence (percent of infected leaves) and disease severity (number of lesions per leaf) were investigated in different regions of Palestine. The results showed a positive correlation between disease incidence and severity.

According to this study, higher disease incidences and severities were recorded in Jenin, Nablus, Tulakrm, Qalqilyah and Salfit. The higher incidence in these regions could be attributed to the wet and humid conditions. The annual rainfall in these regions ranges, approximately, from 494 to $558 \mathrm{~mm}$ per year [11]. Cool and moist environmental conditions are favored for epedimic development of the fungus in cooler olive-growing regions [2,12]. Moist weather conditions favor S. oleagina sporulation, conidium germination and infection [2,12]. It was reported by Obanor et al. (2008) that conidium production was optimal at $15^{\circ} \mathrm{C}$ under high humidity (100\%), whereas conidium germination and infection required continuous free moisture for 12 - $24 \mathrm{~h}$ and temperatures ranging from $5^{\circ} \mathrm{C}$ to $25^{\circ} \mathrm{C}$ [13]. The results of this study are in good agreement with the findings of Obanor et al. (2008) who reported abundant conidium production during spring and autumn, but limited conidium production during the summer months.

To the Authors' knowledge, the present study was the first of its kind, in regard to surveying of disease incidence and severity of OLS in Palestine. Epidemiological studies are needed to determine the latent infection of olive trees by the disease and to assess in more details the climatic conditions for disease development under the Palestinian environmental conditions. This will then enable to plan a control strategy of disease using chemical fungicides and/or tree management strategies and development of a disease forecasting system [14]. The effect of OLS on tree health, fruit yield and olive oil quality also requires further evaluation. This survey was conducted during autumn season and only provides a preliminary assessment of prevalence of OLS during this period.

This study showed that OLS is widely spread in Palestine with all regions being infected. However, further monitoring is needed to better understand the disease incidence and spread in Palestine.

\section{Acknowledgements}

The Authors would like to thank Dr. Azmi Awad, Palestine Technical University-Kadoorie (PTUK)) for facilitating this work by providing the university car. Thanks 
also are due to Dr. Hilmi S. Salem, PTUK for his constructive and objective comments on the manuscript. We would like to thank Mr. Eng. Fares Jabi and the directorates of the Palestinian Ministry of Agriculture for Guidance and help during the project.

\section{REFERENCES}

[1] F. Jabi, “The Olive Tree,” Zain Press, Nablus, 2007.

[2] F. O. Obanor, M. V. Jaspers, E. E. Jones and M. Walter, "Greenhouse and Field Evaluation of Fungicides for Control of Olive Leaf Spot in New Zealand," Crop Protection, Vol. 27, No. 10, 2008, pp. 1335-1342. doi:10.1016/j.cropro.2008.04.007

[3] B. L. Teviotdale, G. S. Sibbett and D. H. Harper, "Several Copper Fungicides Control Olive Leaf Spot,” California Agriculture, Vol. 43, No. 5, 1989, pp. 30-31.

[4] R. Gonzalez-Lamothe, R. Segura, A. Trapero, L. Baldoni, M. A Botella and V. Valpuesta, "Phylogeny of the Fungus Spilocaea oleagina, the Causal Agent of Peacock Leaf Spot in Olive,” FEMS Microbiology Letters, Vol. 210, No. 1, 2002, pp. 149-155.

[5] A. Graniti, “Olive Scab: A Review,” EPPO Bulletin, Vol. 23, No. 3, pp. 377-384.

[6] B. L. Teviotdale and G. S. Sibbett, "Consistent Annual Treatment Helps Future Olive Leaf Spot Control,” California Agriculture, Vol. 49, No. 5, 1995, pp. 27-32. doi:10.3733/ca.v049n05p27

[7] A. J. Macdonald, M. Walter, M. Trought, C. M. Frampton and G. Burnip, "Survey of Olive Leaf Spot in New Zea- land,” New Zealand Plant Protection, Vol. 53, 2000, pp. 126-132.

[8] F. O. Obanor, M. Walter, E. E. Jones and M. V. Jaspers, "Sources of Variation in a Field Evaluation of the Incidence and Severity of Olive Leaf Spot," New Zealand Plant Protection, Vol. 58, 2005, pp. 273-277.

[9] R. C. Seem, "Disease Incidence and Severity Relationships,” Annual Review of Phytopathology, Vol. 22, 1984, pp. 133-150. doi:10.1146/annurev.py.22.090184.001025

[10] F. W. Nutter and P. M. Schultz, "Improving the Accuracy and Precision of Disease Assessments: Selection of Methods and Use of Computer Aided Training Programs," Canadian Journal of Plant Pathology, Vol. 17, No. 2, 1995, pp. 174-184. doi:10.1080/07060669509500709

[11] Palestinian Meteorological Department, 2010. http://www.pmd.ps/ar/index.php

[12] F.O. Obanor, M. Walter, E. E. Jones and M. V. Jaspers, "Effect of Temperature, Relative Humidity, Leaf Wetness and Leaf Age on Spilocaea oleagina Conidium Germination on Olive Leaves," European Journal of Plant Pathology, Vol. 120, No. 3, 2008, pp. 211-222. doi:10.1007/s10658-007-9209-6

[13] F. Sistani, S. S. Ramezanpour and S. Nasrollanejad, "Field Evaluation of Different Fungicides Application to Control Olive Leaf Spot," Australian Journal of Basic and Applied Sciences, Vol. 3, No. 4, 2009, pp. 33413345.

[14] J. R. Viruega and A. Trapero, "Efficacy of KresoximMethyl against Olive Leaf Spot Caused by Spilocaea oleagina,” Acta Horticulture, Vol. 586, 2002, pp. 801-804. 